\title{
Evolution Behavior of Carbides in 2.25Cr-1Mo-0.25V Steel
}

\author{
Zhang Yongtao $^{1}$, Miao Lede ${ }^{2}$, Wang Xiaojun ${ }^{2}$, Zhang Hanqian ${ }^{1,2, *}$ and Li Jinfu ${ }^{1}$ \\ ${ }^{1}$ School of Materials Science and Engineering, Shanghai Jiaotong University, Shanghai 200240, P. R. China \\ ${ }^{2}$ Research Institute, Baoshan Iron \& Steel Co., Ltd., Shanghai 201900, P. R. China
}

\begin{abstract}
The investigation was carried out on the evolution behavior of carbides precipitated in $2.25 \mathrm{Cr}-1 \mathrm{Mo}-0.25 \mathrm{~V}$ steel during heat treatment. Four types of carbides $\mathrm{M}_{3} \mathrm{C}, \mathrm{M}_{23} \mathrm{C}_{6}, \mathrm{M}_{7} \mathrm{C}_{3}$ and $\mathrm{MC}$ were identified. The mass fraction of each type of carbide was calculated and the dissolution of $\mathrm{MC}$ particles was found to occur during tempering. This could be caused by the annihilation of dislocations and the MC carbides precipitated on dislocations became energetically unstable and dissolved into the matrix. In addition, a two-step transformation mechanism was proposed for Cr-Fe-rich carbide. The changes in metallic composition and the average particle size of carbides were also characterized and analysed. [doi:10.2320/matertrans.M2009172]
\end{abstract}

(Received May 12, 2009; Accepted July 23, 2009; Published September 30, 2009)

Keywords: 2.25Chromium-1Molybdium-0.25Vanadium steel, precipitates, dissolution of MC carbide, transformation mechanism

\section{Introduction}

2.25Cr-1Mo-0.25V steel has being widely used for the hydrocracking and hydro-desulfurization reactors in energy industry. Carbide precipitation is the main strengthening mechanism and each type of carbides play different kind of roles. As well known, the fine dispersed strengthening MC carbide retards the microstructural recovery and is important for improving the creep rupture strength of steel. ${ }^{1)}$ The popular $\mathrm{Cr}$-Fe-rich carbide $\mathrm{M}_{7} \mathrm{C}_{3}$ grows easily and usually precipitates on the lath or block boundaries, which caused the migration of grain boundary and, therefore, shortened the time to the onset of acceleration creep. ${ }^{2)}$ Here $\mathrm{M}=\mathrm{Fe}, \mathrm{Cr}$, Mo, $\mathrm{V}$, etc.

Recently, Janovec, ${ }^{3,4)}$ Bhadeshia $^{5)}$ and Pigrova ${ }^{6)}$ et al. have attributed considerable attention to the precipitation behaviours of carbide during long-term aging. However, there is seldom detailed investigation on the carbide evolution behaviours of low-alloyed $\mathrm{Cr}-\mathrm{Mo}-\mathrm{V}$ steels during heat treatment, such as mass fraction, chemical composition and particle size. It usually plays a key role on the stability and resistance to creep and to hydrogen damage. ${ }^{7-10)}$

\section{Experimental Procedures}

The hot-rolled steel plate with a thickness of $20 \mathrm{~mm}$ used in the investigation came from a $150 \mathrm{~kg}$ vacuum-induction melt with the chemical composition given in Table 1. Then, the heat treatment was as follows: 1 hour at $940^{\circ} \mathrm{C}$, a two-step water quenching, followed by 2, 5 and 10 hours tempering respectively at $710^{\circ} \mathrm{C}$, air cooling.

The precipitate was electrolytically extracted using the $5 \% \mathrm{KCl}-1 \%$ Citric acid distilled water solution. The residue was separated using a membrane filter with $0.05 \mu \mathrm{m}$ pores. Therefore, the carbide's mass fraction of the sample can be expressed as:

$$
f=m_{\mathrm{c}} /\left(m_{0}-m_{t}\right)=m_{\mathrm{c}} / \Delta m \times 100 \%
$$

where $m_{\mathrm{c}}$ is the mass of carbide extracted from the specimen,

*Corresponding author, E-mail: hqzhang1964@126.com
Table 1 Nominal composition of the experimental steel (mass \%).

\begin{tabular}{ccccccccc}
\hline $\mathrm{C}$ & $\mathrm{Mn}$ & $\mathrm{Si}$ & $\mathrm{P}$ & $\mathrm{S}$ & $\mathrm{Cr}$ & $\mathrm{Mo}$ & $\mathrm{V}$ & $\mathrm{Fe}$ \\
\hline 0.13 & 0.55 & $<0.05$ & $<0.012$ & $<0.003$ & 2.20 & 1.02 & 0.24 & balance \\
\hline
\end{tabular}

Table 2 Identification of carbide precipitated in the $2.25 \mathrm{Cr}-1 \mathrm{Mo}-0.25 \mathrm{~V}$ steel during quenching and tempering.

\begin{tabular}{cl}
\hline Specimens & Identified carbides \\
\hline Q & $\mathrm{M}_{3} \mathrm{C}+\mathrm{M}_{7} \mathrm{C}_{3}+\mathrm{MC}$ \\
QT2 & $\mathrm{M}_{7} \mathrm{C}_{3}+\mathrm{MC}+\mathrm{M}_{23} \mathrm{C}_{6}$ \\
QT5 & $\mathrm{M}_{7} \mathrm{C}_{3}+\mathrm{MC}+\mathrm{M}_{23} \mathrm{C}_{6}$ \\
QT10 & $\mathrm{M}_{7} \mathrm{C}_{3}+\mathrm{MC}+\mathrm{M}_{23} \mathrm{C}_{6}$ \\
\hline
\end{tabular}

Note: Q-quenched sample; QT2, QT5 and QT10-samples quenched at first and then tempered for 2,5 and $10 \mathrm{~h}$, respectively.

$m_{0}$ is the original mass of specimen before electrolyzing and $m_{t}$ is the final mass of specimen after electrolyzing.

The extracted carbide powder was analyzed by Rigaku D/ max-2550 X-Ray diffractometer with $C u K_{\alpha}$ radiation and graphite monochromators. The diffraction data was collected for each specimen from 30 to $90^{\circ} 2 \theta$ with a step width of $0.02^{\circ}$ and a count time of $2.0 \mathrm{~s}$ per step.

Detailed microanalyses were performed on the carbon extraction replicas, with an average of at least 20 isolated particles on each specimen being analyzed, covering an area of several grid squares. An Oxford energy-dispersive X-ray spectrometer attached to a Jeol H800 scanning transmission electron microscope was used for all the analyses. Counts from each specimen were kept at $500 \pm 50$ counts s$^{-1}$ to ensure a constant-intensity beam.

At last, the average particle size of carbide powder was measured using the MS-2000 particle size analyzer made by Malvern company. The refractive index is 2.42 .

\section{Results}

\subsection{Carbide identification}

The carbide identification result is given in Table 2. Metastable Fe-rich $\mathrm{M}_{3} \mathrm{C}$ dissolved rapidly and $\mathrm{M}_{23} \mathrm{C}_{6}$ 
precipitated during high temperature tempering. Although dissolution of $\mathrm{Cr}-\mathrm{Fe}$-rich carbide has been reported as a more rapid process than dissolution of $\mathrm{V}$-Mo-rich carbide, $\mathrm{M}_{7} \mathrm{C}_{3}$ also existed in the quenching state because of it's difficult complete dissolution even at a very high austenitizing temperature. ${ }^{11)}$ The $\mathrm{M}_{7} \mathrm{C}_{3}$ could nucleate and grow during hot rolling or subsequent air cooling process as auto-tempering mechanism. Finally, no Mo-rich carbide formed and the role of molybdenum was as a solid solution hardener.

\subsection{Carbide amount}

Figure 1 shows the mass fraction of each phase which was calculated using the Rietveld full-pattern fitting algorithm ${ }^{12)}$ and suggested dissolution of fine MC particle after 10 hours tempering (Fig. 2(c)). It also can be seen that the amount of carbide $\mathrm{M}_{23} \mathrm{C}_{6}$ was little and decreased gradually in contrast with the increase of $\mathrm{M}_{7} \mathrm{C}_{3}$. Besides the individual nucleation of $\mathrm{M}_{7} \mathrm{C}_{3}$, it could result from the transformation of $M_{3} C \Rightarrow$ $M_{7} C_{3}$ and $M_{23} C_{6} \Rightarrow M_{7} C_{3}$.
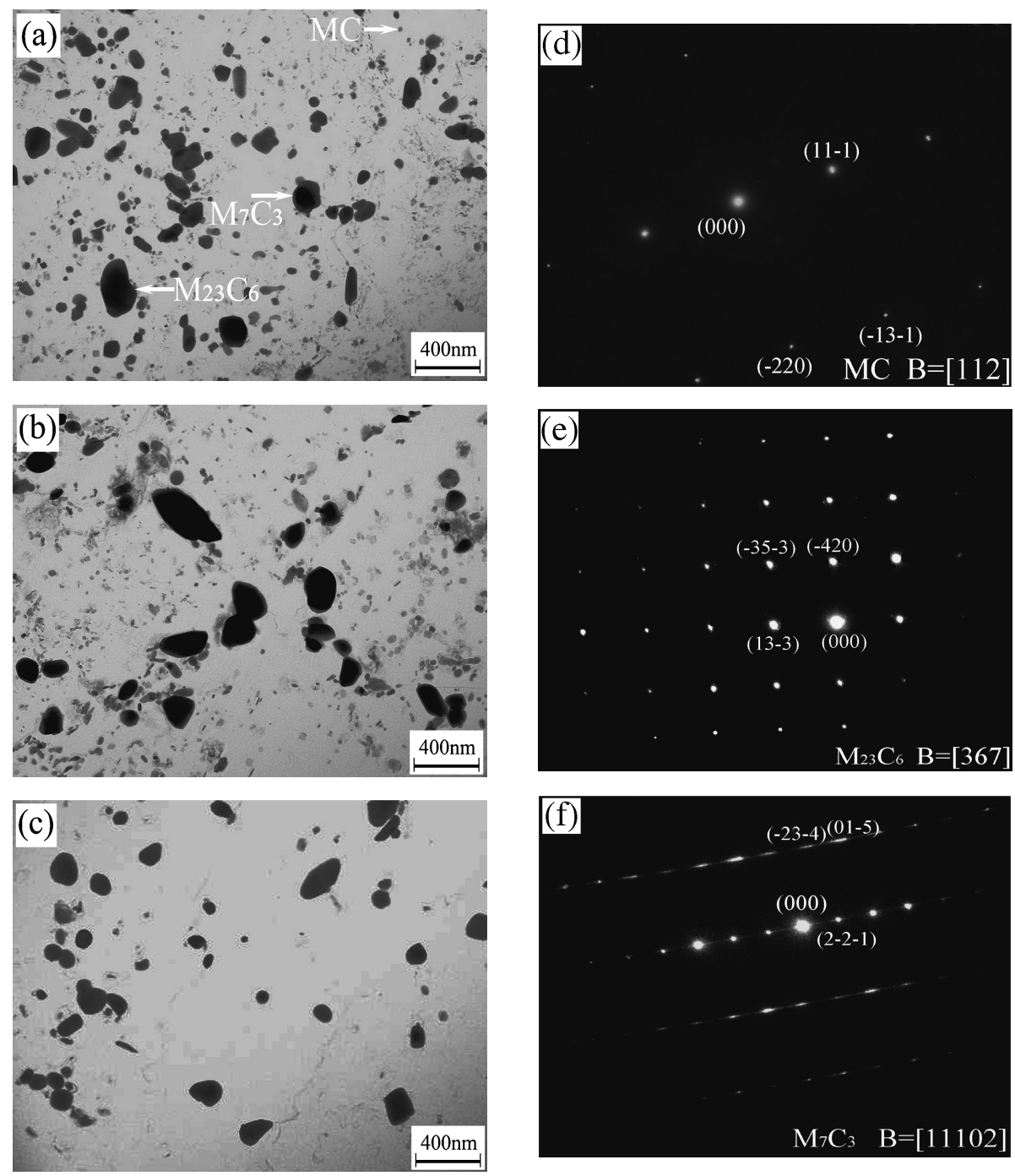

Fig. 1 Mass fractions evolution of carbide in the $2.25 \mathrm{Cr}-1 \mathrm{Mo}-0.25 \mathrm{~V}$ steel as-tempered for $2 \mathrm{~h}$ to $10 \mathrm{~h}$ calculated using the Rietveld algorithm.

Fig. 2 Transmission electron micrographs of the extraction replicas from the $2.25 \mathrm{Cr}-1 \mathrm{Mo}-0.25 \mathrm{~V}$ steel as tempered for (a) $2 \mathrm{~h}$, (b) $5 \mathrm{~h}$ and (c) $10 \mathrm{~h}$, respectively and the select area diffraction electron pattern for each kind of carbides (d) $\mathrm{MC}_{2}(\mathrm{e}) \mathrm{M}_{23} \mathrm{C}_{6}$ and (f) $\mathrm{M}_{7} \mathrm{C}_{3}$, respectively. 

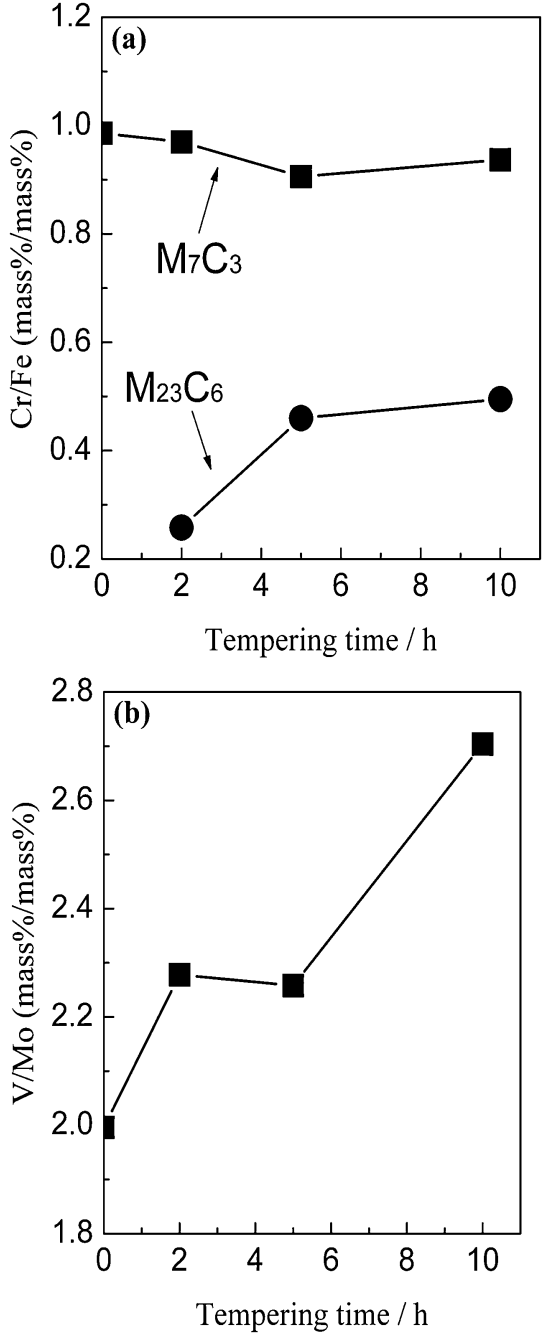

Fig. 3 Inflence of tempering time on the average chemical composition of the metallic component in carbide phases: (a) $\mathrm{M}_{7} \mathrm{C}_{3}$ and $\mathrm{M}_{23} \mathrm{C}_{6}, \mathrm{Cr} / \mathrm{Fe}$; (b) $\mathrm{MC}, \mathrm{V} / \mathrm{Mo}$

\subsection{Metallic composition of carbide}

Complicated carbide in low-alloyed CrMoV steels can be characterized as multicomponent systems containing more metallic elements. However, some minor elements do not play any important influence on the carbide transformation due to their limited concentration. Hence, to make the survey simple, the $\mathrm{Cr} / \mathrm{Fe}$ ratio was chosen to be the parameter for characterizing the $\mathrm{Cr}-\mathrm{Fe}$-rich $\mathrm{M}_{23} \mathrm{C}_{6}$ and $\mathrm{M}_{7} \mathrm{C}_{3}$ carbides and similarly, the $\mathrm{V} / \mathrm{Mo}$ ratio was considered for $\mathrm{V}$-Mo-rich MC. The results for $M_{7} C_{3}$ and $M_{23} C_{6}$ are shown in Fig. 3(a). With increasing time of tempering, the $\mathrm{Cr} / \mathrm{Fe}$ value for $\mathrm{M}_{7} \mathrm{C}_{3}(0.9-1)$ decreased at first slightly and then kept stable. This may be also caused by the transformation of $M_{3} C \Rightarrow$ $M_{7} C_{3}$ and $M_{23} C_{6} \Rightarrow M_{7} C_{3}$ during tempering. From a thermodynamical viewpoint, $\mathrm{Cr} / \mathrm{Fe}$ ratio of $\mathrm{M}_{23} \mathrm{C}_{6}(0.1-$ $0.5)$ increased at first intensively and then slightly, which suggested the $\mathrm{M}_{23} \mathrm{C}_{6}$ reached a more stable state. On the other hand, the changes of $\mathrm{V} / \mathrm{Mo}$ ratio (2.0-2.8) corresponded to the variation of mass fraction of MC phase well (Fig. 3(b)). During the initial tempering, the higher affinity of $\mathrm{V}$ for $\mathrm{C}$ would dominate and lead to a slight decrease of Mo content, which brought about the first increase of $\mathrm{V} / \mathrm{Mo}$
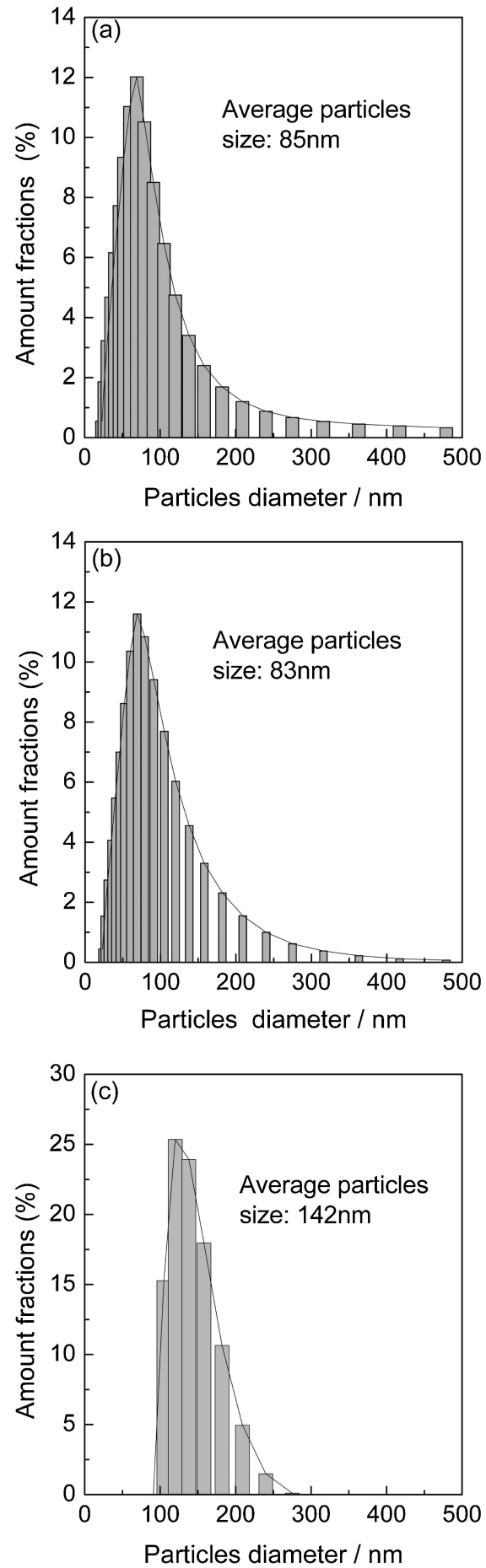

Fig. 4 Carbides particles size distribution for the $2.25 \mathrm{Cr}-1 \mathrm{Mo}-0.25 \mathrm{~V}$ steel as tempered for (a) $2 \mathrm{~h}$, (b) $5 \mathrm{~h}$ and (c) $10 \mathrm{~h}$, respectively.

ratio. When the dissolution of metastable MC particles precipitated on dislocations occurred, the most stable MC carbide remained and the average $\mathrm{V} / \mathrm{Mo}$ ratio enhanced again.

\subsection{Average carbide particle size}

Figure 4 shows the size distribution histograms of the carbide powder for different tempering time. The histograms approach to a lognormal distribution and remain integrated at the right tail of the distribution. After tempering for 2 and 5 hours, the peaks both centered at ahout $75 \mathrm{~nm}$ and while the 

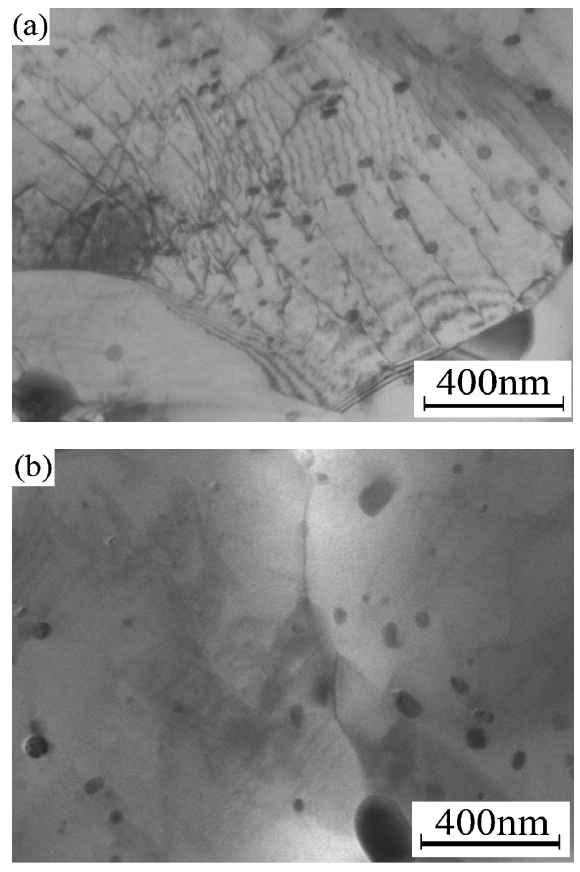

Fig. 5 TEM of the large amount of MC particles precipitated or dissolved on the dislocations in the $2.25 \mathrm{Cr}-1 \mathrm{Mo}-0.25 \mathrm{~V}$ steel as-tempered for (a) $5 \mathrm{~h}$ and (b) $10 \mathrm{~h}$, respectively.

peak centered at about $135 \mathrm{~nm}$ at 10 hours tempering. Apparently, the coarsening resulted from the dissolution of fine MC particles, which was different from the normal Ostwald ripening.

\section{Discussion}

As mentioned above, these evolution behaviours were closely related to the dissolution of MC carbide and the mutual transformation of $\mathrm{Cr}$-Fe-rich carbide. Therefore, it can be discussed in detail as follows.

\subsection{Dissolution of MC}

It is well known that the MC phase is thermally stable and generally dissolves during austenization process and the solubility product of $\mathrm{VC}$ in the equilibrated ferrite is given by the following equation: ${ }^{13)}$

$$
\log \left([V \%] *[C \%]^{0.875}\right)_{\alpha}=5.65-9340 / T
$$

where $T$ is the absolute temperature and \% denotes mass $\%$. Hence, it could be explained as follows: Immediately after quenching many dislocations are present in the matrix, and thus MC particles precipitated preferably on the dislocations during tempering because of the strong interaction between them (Fig. 5(a)). During this stage the dislocations were pinned by the precipitated MC particles and the further recovery was apparently delayed. However, since the MC precipitate did not decorate all the segments of dislocations and the thermally unstable dislocations should climb and be annihilated. As a result, the MC precipitate lost the stable precipitation sites. These processes could also be explained by the following energy relation: Gibbs free energy of the local area for a precipitated state, $\Delta G_{1}$, and a state where a dislocation is detached from the precipitated particles just before dissolution of the precipitates, $\Delta G_{2}$, are expressed by the next equations:

$$
\Delta G_{1}=U_{\text {prep }}+U_{\text {disl }}+U_{\gamma}+U_{\text {interaction }}
$$

and

$$
\Delta G_{2}=U_{\text {prep }}+U_{\text {disl }}+U_{\gamma}
$$

where, $U_{\text {prep }}, U_{\text {disl }}, U_{\gamma}$ and $U_{\text {interaction }}$ are free energy change due to precipitation, elastic energy of a dislocation, increase in interfacial energy between the precipitated particles and the matrix and elastic interaction energy between the dislocation and the precipitated particles, respectively. The difference in the free energy of the two states is

$$
\Delta G_{2}-\Delta G_{1}=-U_{\text {interaction }}
$$

$U_{\text {interaction }}$ is negative due to precipitation of MC particles on dislocations. So, $\Delta G_{2} \geq \Delta G_{1}$. So, if annihilation of highdensity dislocations was occurred during tempering, the MC carbide would become unstable immediately and dissolve into the matrix (Fig. 5(b)). However, Tamura et al. have found that $\mathrm{MC}$ can dissolve at first and then precipitate again during long-term aging. ${ }^{14,15)}$ In a word, dissolution of MC into matrix maybe occurred temporarily after 10 hours tempering.

\subsection{Transformation of $\mathrm{Cr}$-Fe-rich carbides}

$\mathrm{M}_{23} \mathrm{C}_{6}$ usually does not belong to the equilibrium phase in $\mathrm{CrMoV}$ steels with bulk $\mathrm{Cr}$ content lower than 3 mass\%. ${ }^{16)}$ Nevertheless, the precipitation of $\mathrm{M}_{23} \mathrm{C}_{6}$ was observed in such steels. Senior ${ }^{17)}$ and Janovec, ${ }^{18)}$ exhibited the scheme of carbide precipitation in the low-alloyed Chromium-Molybdenum-Vanadium steels during long-term aging. According to this scheme, $\mathrm{M}_{23} \mathrm{C}_{6}$ was replaced by $\mathrm{M}_{7} \mathrm{C}_{3}$. Smith ${ }^{19)}$ also found the $\mathrm{M}_{23} \mathrm{C}_{6}$ particles in the Chromium-MolybdenumVanadium steels with $0.2 \mathrm{C}, 0.5 \mathrm{Mo},<1.5 \mathrm{Cr}$, and $<0.4 \mathrm{~V}$ (mass\%). He explained this as a result of the stabilizing role of Mo on the carbide $\mathrm{M}_{23} \mathrm{C}_{6}$ in steels with lower $\mathrm{Cr}$-content. According to Senior, Smith and Janovec, the optimum conditions for precipitation of metastable $\mathrm{M}_{23} \mathrm{C}_{6}$ phase are also at lower $\mathrm{Cr}$ and higher Mo content in ferritic matrix. Carbide $\mathrm{M}_{7} \mathrm{C}_{3}$ is Mo-poor, and fine, Mo-rich MC particles take only a slight mass fraction. Therefore, the Mo content in ferritic matrix was relatively high, and in the areas with reduced $\mathrm{Cr}$-content, such as around $\mathrm{M}_{7} \mathrm{C}_{3}$ phase, it could result in the formation of individual carbide $\mathrm{M}_{23} \mathrm{C}_{6}$. On the other hand, the metastable $\mathrm{M}_{23} \mathrm{C}_{6}$ particles didn't represent the lowest free energy state and ultimately transformed with time as the material approached equilibrium. Hence, there was maybe a two-step transformation mechanism for the $\mathrm{M}_{7} \mathrm{C}_{3}$ formation: $M_{3} C \Rightarrow M_{7} C_{3}$ and then followed $M_{23} C_{6} \Rightarrow M_{7} C_{3}$. In summary, the fine $\mathrm{MC}$ and big $\mathrm{M}_{7} \mathrm{C}_{3}$ particles are stable in the steel, which is identical to the Fig. 6. ${ }^{18)}$

\section{Conclusions}

(1) Four types of carbides $M_{3} C, M_{23} C_{6}, M_{7} C_{3}$ and $M C$ were identified and the mass fraction of each type of carbides in steel was calculated and analysed.

(2) Dissolution of MC phase was found, which could be 


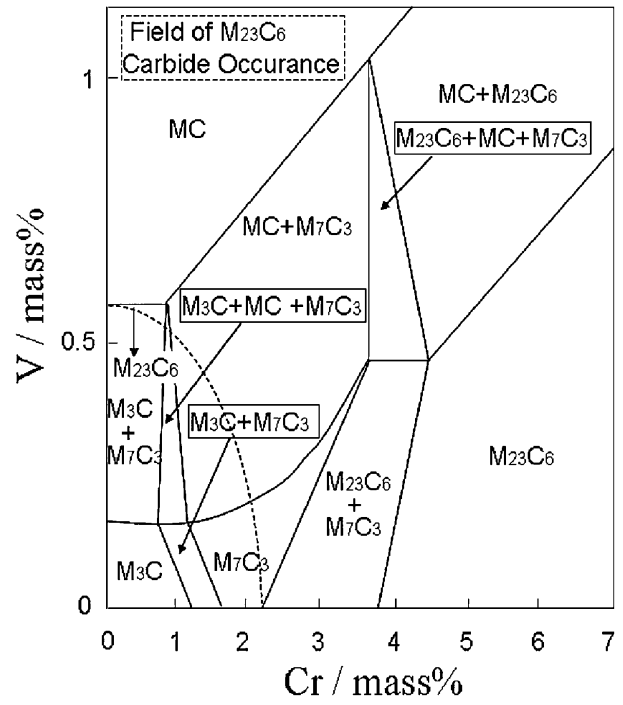

Fig. 6 Constitution diagram for $0.2 \mathrm{C}-0.7 \mathrm{Mo}-\mathrm{yCr}-\mathrm{zV}$ steel at the $700^{\circ} \mathrm{C} .{ }^{18}$ )

caused by the annihilation of dislocations during tempering. (3) A two-step transformation mechanism was proposed for Cr-Fe-rich carbides during early tempering: $M_{3} C \Rightarrow M_{23} C_{6}$ and then followed $M_{23} C_{6} \Rightarrow M_{7} C_{3}$.

(4) The values of $\mathrm{Cr} / \mathrm{Fe}$ ratio ranged between 0.1 and 0.5 for $\mathrm{M}_{23} \mathrm{C}_{6}$, between 0.9 and 1 for $\mathrm{M}_{7} \mathrm{C}_{3}$ and the $\mathrm{V} / \mathrm{Mo}$ ratio ranged between 2.0 and 2.8 for $\mathrm{MC}$.

(5) The average particle size increased intensively after 10 hours tempering which was caused by the dissolution of fine MC particles.

\section{Acknowledgement}

This work was financially sponsored by the New Products Development Research Project of Shanghai Baoshan Iron \& Steel research institute (X08ECEJ160).

\section{REFERENCES}

1) M. Taneike, F. Abe and K. Sawada: Nature 424 (2003) 294-296.

2) F. Abe, S. Nakazawa, H. Araki and T. Noda: Metall. Mater. Trans. A 23 (1992) 469-477.

3) J. Janovec, M. Svoboda, A. Kroupa and A. Vyrostková: J. Mater. Sci. 41 (2006) 3425-3433.

4) J. Jannovec and A. Výrostková: J. Mater. Sci. 27 (1992) 6564-6572.

5) H. K. D. H. Bhadeshia: ISIJ Int. 41 (2001) 626-640.

6) G. D. Pigrova: Met. Sci. Heat Treat. 45 (2003) 84-87.

7) T. Yokota and T. Shiraga: ISIJ Int. 43 (2003) 534-538.

8) K. Maruyama, K. Sawada and J. Koike: ISIJ Int. 41 (2001) 641-653.

9) F. Abe: Curr. Opin. Solid State Mater. Sci. 8 (2004) 305-311.

10) S. M. Schlögl, J. Svoboda and E. Van der Giessen: Acta Mater. 49 (2001) 2227-2238.

11) C. Wu, V. Sahajwalla and P. Krauklis: ISIJ Int. 36 (1996) 347-353.

12) Y. T. Zhang, H. B. Han, L. D. Miao, H. Q. Zhang and J. F. Li: Mater. Charact. doi:10.1016/j.matchar.2009.03.009.

13) Q. L. Yong, S. G. Yan and H. Z. Pei: J. Iron Steel Res. Int. 10 (1998) 63-67.

14) M. Tamura, K. Ikeda and H. Esaka: ISIJ Int. 41 (2001) 908-914.

15) M. Tamura, T. Iida and H. Kusuyama: ISIJ Int. 44 (2004) 153-161.

16) K. W. H. Andrews Hughes and D. J. Dyson: J. Iron Steel Inst. 210 (1972) 337-350.

17) B. A. Senior: Mater. Sci. Eng. A 103 (1988) 263-271.

18) J. Janovec, A. Vyrostkova and M. Svoboda: Metall. Mater. Trans. A 25A (1994) 267-275.

19) E. Smith and J. Nutting: J. Iron Steel Inst. 192 (1957) 314-329. 